\title{
Application Research on OVP Blended Teaching Method in Microwave Technology and Antennas
}

\author{
Li Zhu, Xiangjun Gao, Cunqian Feng, Jiangang Liang, Yawei Wang \\ Air Force Engineering University, Xi'an, China \\ Email: tgzb821@163.com
}

How to cite this paper: Zhu, L., Gao, X. J., Feng, C. Q., Liang, J. G., \& Wang, Y. W. (2021). Application Research on OVP Blended Teaching Method in Microwave Technology and Antennas. Open Journal of Social Sciences, 9, 584-592.

https://doi.org/10.4236/jss.2021.99043

Received: May 24, 2021

Accepted: September 26, 2021

Published: September 29, 2021

\begin{abstract}
The OVP blended teaching method is an effective teaching method based on the engineering teaching practice and the course system of microwave technology and antenna. In the teaching process, we should emphasize the combination of network, virtualization and project teaching mode, and attach importance to the application of new educational platform and educational resources, especially the diversification and cutting-edge concept of curriculum team, which makes teaching methods diversify and engineering. A number of knowledge points throughout the whole design process, to achieve the effective combination of technical principles and engineering practice. It enables students to really participate in the process of teaching and learning, and help to cultivate their comprehensive abilities of practice and innovation.
\end{abstract}

\section{Keywords}

Blended Teaching Method, OVP, Microwave Technology and Antennas

\section{Introduction}

With the continuous development of information technology and the rapid popularization of network teaching, it provides a new support for the educational revolution, promotes the reform of education, and leads to the innovation of educational concepts. Under this background, education puts more emphasis on the basis of knowledge learning and the ability development as the core. It focuses on promoting students' individual development. Microwave technology and antenna is a professional basic theoretical course for undergraduates majoring in electronics and communication, which takes into account both basic theories and engineering techniques (Wang et al., 2018) (Li, 2018). In practice, 
there are a series of problems such as the difficulty of theoretical knowledge, the abstraction of concepts the disconnection between theory and engineering and so on (Ping et al., 2017) (Cao et al., 2017). It has seriously affected the quality of teaching and the learning effect of students. How to set up and clarify the contents closely related to the training of students in limited time is closely related to engineering practice, which puts forward higher requirements for innovative teaching mode and teaching method.

According to the actual teaching of the course and closing to the engineering practical, this paper adopts OVP Blended Teaching Method. It reorganizes, mixes, intersects and connects the contents of multiple courses and knowledge points to establish a comprehensive large project teaching mode. It can help to transform and expand the students' thinking perspective and realize the effective combination of technical principle and engineering practice.

\section{The OVP Blended Teaching Method}

The OVP blended teaching method is a hybrid teaching which represents online learning + virtual construction + project driven. It mainly describes the four links of project traction, cooperative research, seminar teaching and practical application. It is an effective teaching method which is concise from the radar antenna system, microwave RF devices and other content, especially for the undergraduate course system of electronics and communication.

\subsection{0: Online}

The online here is not a purely web-based learning, but an effective combination of online learning and traditional learning. The teaching resources can be shared through online learning resources and textbooks. After the teacher publishes the topic, the students can search the relevant knowledge information on the Internet, and can also deep learning in the relevant learning platform. The foreign famous online learning platforms include Coursera, eDX, KhanAcademy, etc. In China, there are China University MOOC, Tsinghua Xuetang online, Netease cloud classroom, etc. According to the important knowledge points of microwave technology and antenna course, we developed a synchronous course on the Tsinghua Xuetang online platform, as shown in Figure 1.

In the process of teaching, teachers release course videos, electronic textbooks, homework exercises and final examination questions through the learning platform to provide students with learning content. At the same time, all kinds of notices, such as online answering time, will be released promptly on the platform bulletin board to remind students of attention and related auxiliary materials at each stage. In the discussion area on the platform, besides answering the students' questions in time, teachers will also set up a dynamic column of high-tech development trends, and introduce the frontiers of Metamaterials, Terahertz technology, MMIC and high-power microwave and etc. The summary column is set up to sort out and summarize the contents of each chapter, which 


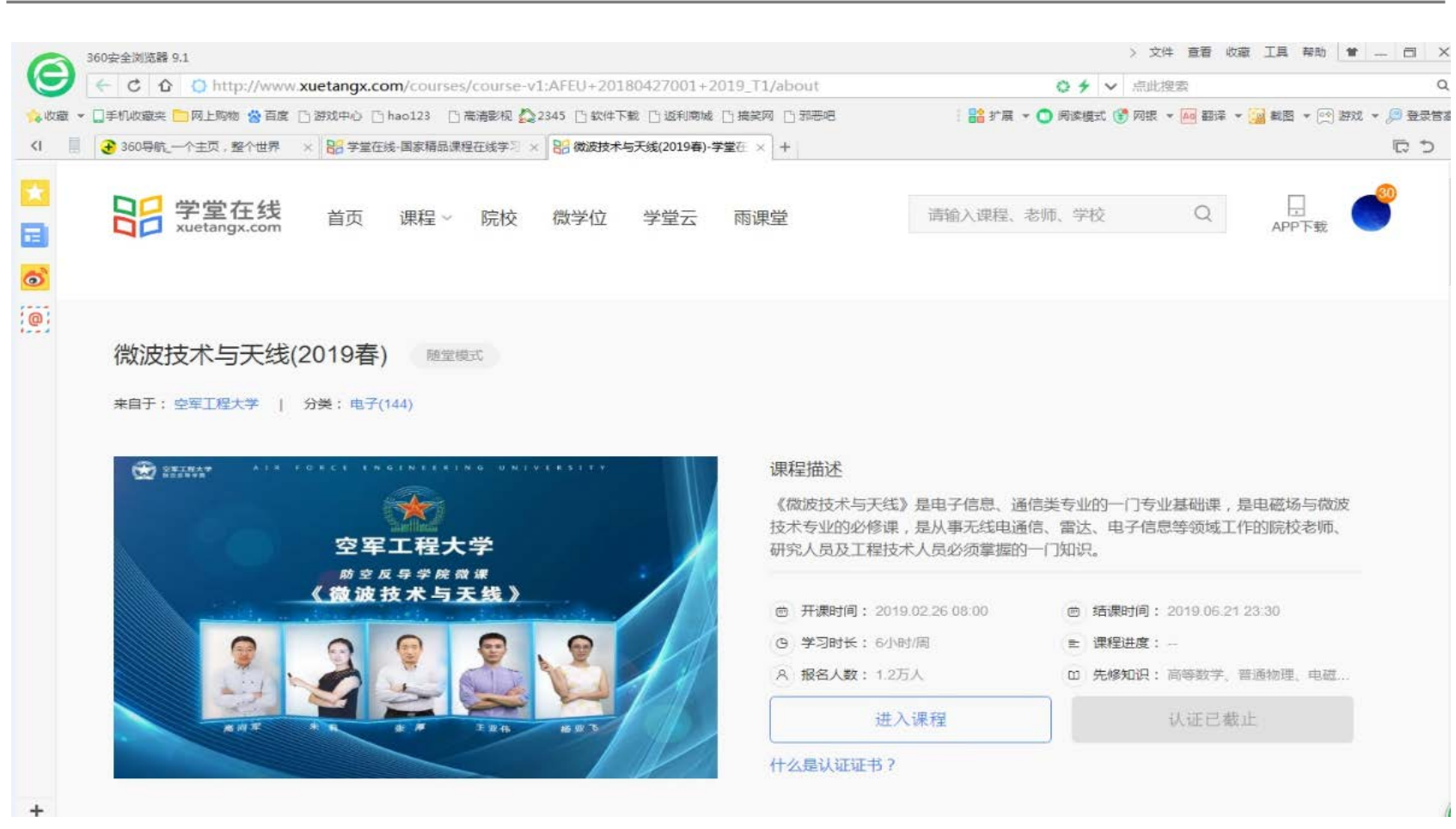

Figure 1. The courses micro-lectures (http://www.xuetangx.com/courses/course-v1:AFEU+20180427001+2019_T1/about).

is convenient for students to review. We set up Q \& A columns to answer questions students encounter when doing their homework. The FAQ and brainstorming column is opened to encourage students to bring some innovative thinking and stimulate students' interest in learning. Through online learning, students can not only learn the course comprehensively and systematically, but also enhance communication and interaction with teachers.

\subsection{V: Virtual}

Microwave technology and antenna is a theoretical course. For beginners, because it is the first time that they study some common concepts, systems and methods in microwave engineering, including Microwave Transmission Line theory, Guide Wave system, Microwave Net theory, Microwave components and Antenna basic knowledge involved in the course. These new concepts enable students to directly stride from some common intuitive objects in daily life, such as radio, television, wireless communication, to an abstract and invisible high-frequency field. Moreover, in teaching, there are many formulas, tedious derivation, complex diagrams and lines, easy to confuse, and learning is boring, which objectively increases the difficulty of learning. These new concepts enable students to stride directly into an abstract and invisible high-frequency field from some common visual objects in daily life, such as radio, television, wireless communication. In addition, there are many formulas which are tedious derivation, complicated drawing and lines which are easy to be confused in the teaching.

In view of the common or difficult problems in the course learning, we use professional electromagnetic simulation software to establish different system 
models, create a dynamic and real-time virtual environment, which is applied to the course teaching. Through numerical simulation, the electromagnetic field distribution and wave propagation of complex structure are presented directly and vividly in front of students, so that students can visualize complex structure and abstract concept, as shown in Figure 2. At the same time, in the course of teaching, we combine the mathematical modeling, virtual simulation, and parameter modification of the theoretical model. It can cultivate students' ability to analyze and solve problems, effectively stimulate students' interest in learning and improve the quality of classroom teaching.

\subsection{P: Project}

The whole course contents are reintegrated and optimized. According to the idea of modularization, close to the needs of all kinds of scientific research projects, the course content is structured into a number of specific projects for traction teaching around the new technology, new breakthrough, new application and other aspects. The basic theory, new technology and design method are covered in the course of project explanation.

For specific projects, students are encouraged to spontaneously form research groups after class according to different research starting points, and carry out personalized research on specific problems. At the same time, it also encourages students to exchange their research results with teachers, learn from each other, and change the traditional teacher based philosophy. In the classroom, each research group exchanges results with each other, and dialectic discuss on different research directions, research ideas, research methods and research results. Everyone put their heads together. So the team research effects can be realized. In this process, the teacher should not only be a deep participant, but also be a qualified judge. It will really inspire, guide and enhance. Through virtual simulation and experiment, the correctness and feasibility of the method are tested. So it is ultimately attributed to the project itself, to find the root of its design, and to restore its design process. It strengthens students' innovative thinking and engineering

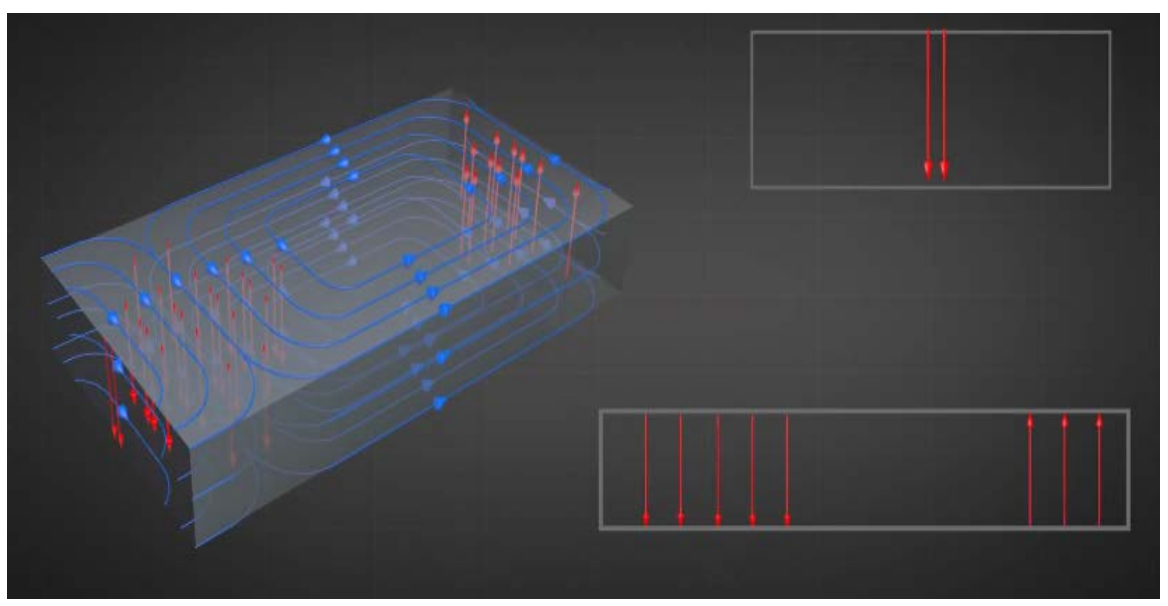

Figure 2. Microwave simulation model. 
practice ability.

The OVP Blended Teaching Method emphasizes the basic theory study while focusing on the engineering realization and application of new technology and methods. It needs not only teachers' guidance and support, but also students' in-depth participation, so as to continuously improve students' logical thinking ability, problem-solving innovation ability, contract cooperation ability and internal motivation of self-worth.

\section{Teaching Examples}

\subsection{Course Content Setting}

According to the talent training plan and curriculum standards, combined with the learning basis of the previous courses, the teaching contents are optimized and reorganized, and the theoretical knowledge is integrated with the real project cases. The microwave components and antennas in the course are integrated into 10 projects.

The project contents are closely related to the RF devices and antenna forms commonly used in radar system, especially the antenna. It is specially designed for the actual project. Based on the function of antenna feeder system, it is divided into the Directional Antenna, Monopulse Antenna, Phased Array Antenna, Parabolic Antenna, etc. Each antenna type has a special topic which contents can cover antenna basic parameters, array theory, pattern synthesis and so on. The emphasis is on the design idea, design process, implementation methods, etc., so as to develop students' ability of systematic thinking, engineering practice and teamwork ability.

\subsection{Course Teaching Mode}

The OVP Blended Teaching Method is adopted to combine classroom learning with online learning. And project driven teaching is carried out with students as the core. Online, students can consult a large number of literatures, teaching video resources viewing, project background investigation, participate in the discussion of teaching information released by teachers, and cooperate with the team to publish topic selection information, $\mathrm{Q}$ and $\mathrm{A}$, so as to lay the foundation for discussion and communication in classroom teaching. Offline with the teaching content, we should elaborate intensive teaching of theoretical content, debate the cooperative research results, establish various research models, verify the virtual simulation plat, analyze and preset the project practice. Finally, we can realize the feasibility evaluation and verification of the project itself, as shown in Figure 3. Through effective teaching activities, classroom knowledge and ability training are integrated into project teaching, so that students can really participate in the process of teaching and learning, and achieve the ability of knowledge learning and application, problem analysis and solution, engineering design and practice, team communication and cooperation. 


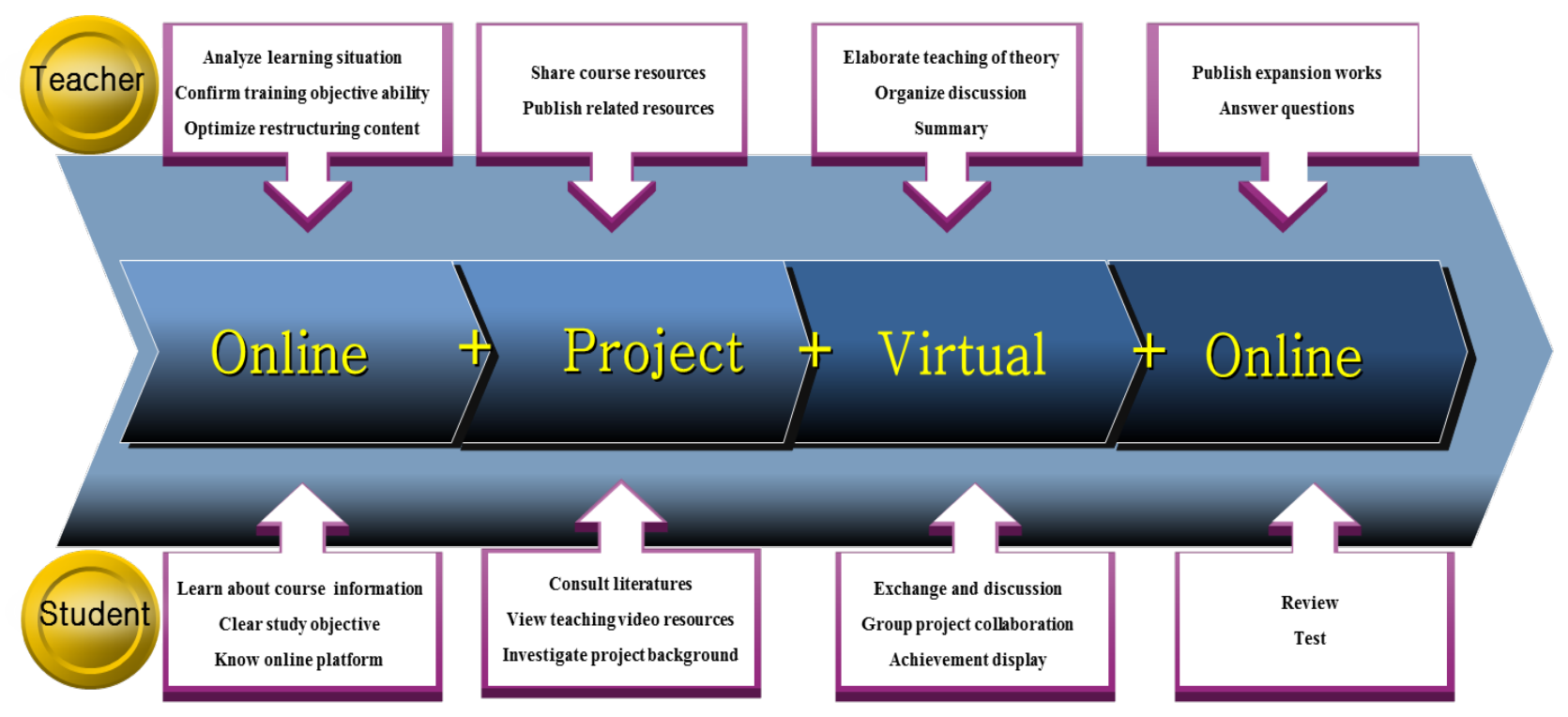

Figure 3. The block diagram of mixed teaching mode.

\subsection{Classroom Organization and Implementation}

We select a certain type of radar antenna project as the teaching content. This antenna is a kind of array antenna with high gain, which requires 360 degree mechanical scanning in azimuth plane, simple phase scanning function in elevation plane and certain angle measurement accuracy. Before this class, students have learned and mastered the basic theory of typical antenna element and array antenna. But at the beginning, students were still unable to start facing the huge and complex array antenna. We use the OVP Blended Teaching Method to disassemble and reassemble the antenna array, so as to guide students to really enter the engineering design and learn the design concept and method of the antenna completely.

Before class, Students should review the relevant knowledge. The basic working principle of symmetric dipole antenna has been mastered by students in the introduction of basic antenna theory, as shown in Figure 4. Through students can be guided to review by online publishing of thinking questions, MOOC and other resources after class, so as to further understand and solidify knowledge. Meanwhile discussion topic was arranged online. And students discuss in group.

In the course, firstly the radar antenna is divided into the most basic symmetric dipole antenna. Then each project team selects a representative to talk about the discussion topic arranged before class. And teacher comments on this, as shown in Figure 5. After that, focusing on the performance index of the radar antenna, the antenna array is recombined according to the design objectives of gain, beam width and sidelobe level, as shown in Figure 6.

This process is interspersed with the new knowledge of the antenna array pattern multiplication principle, beam width, radar angle measurement accuracy, array synthesis and so on. And the HFSS high-frequency 3D field simulation software is applied to each link for modeling and simulation, as shown in Figure 7. 

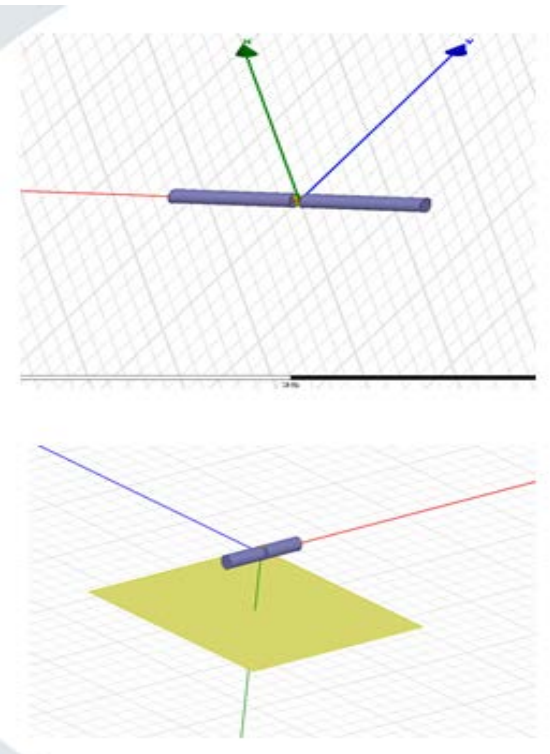

Figure 4. Basic symmetric dipole antenna.
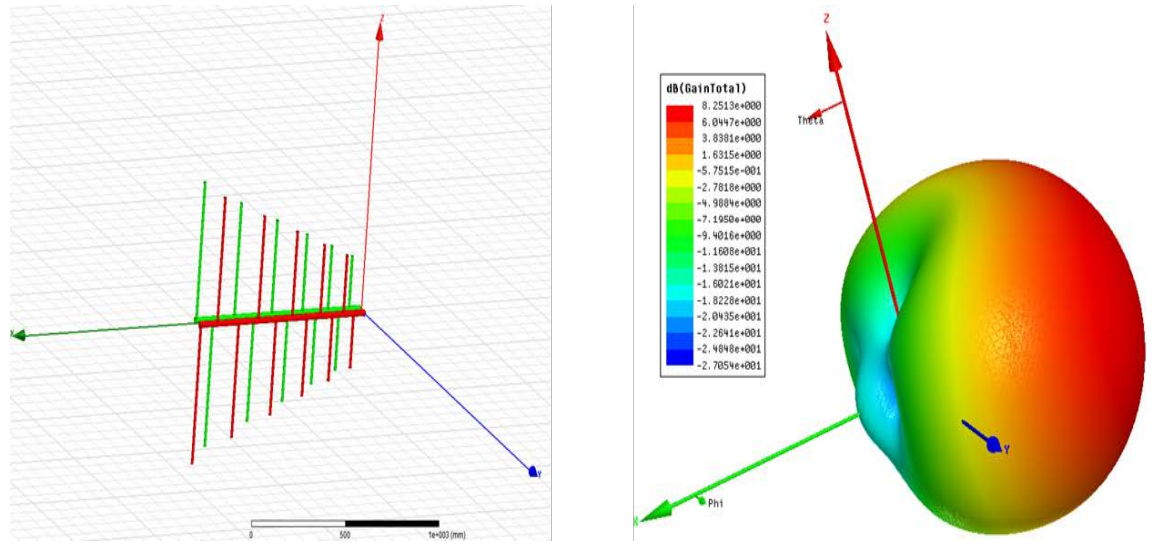

Figure 5. The discussion topic arranged.

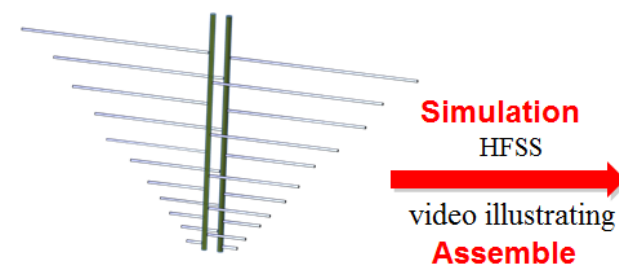

Antenna element
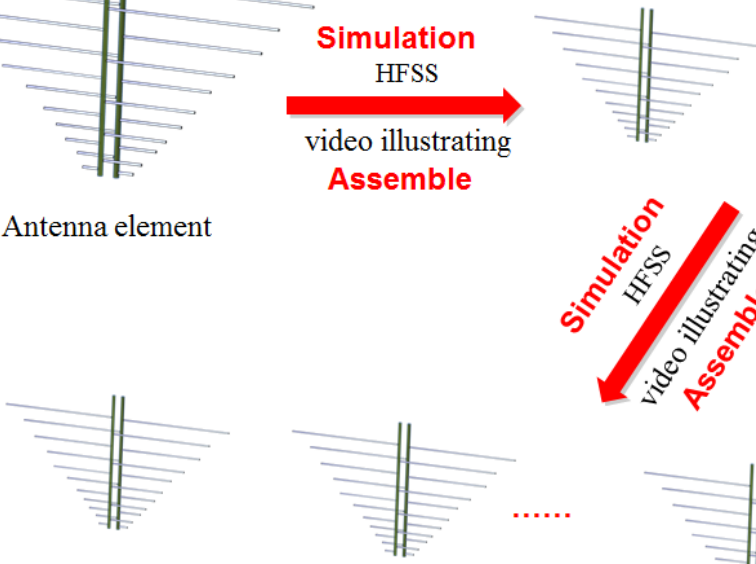

Assemble

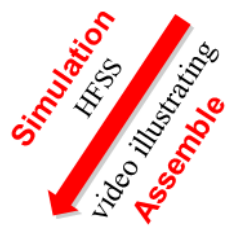

Antenna array

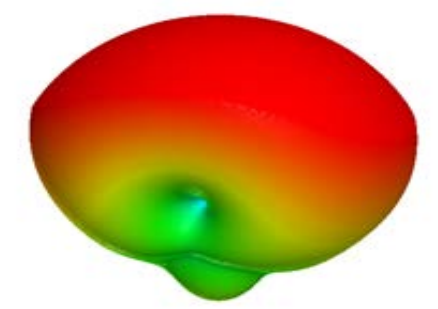




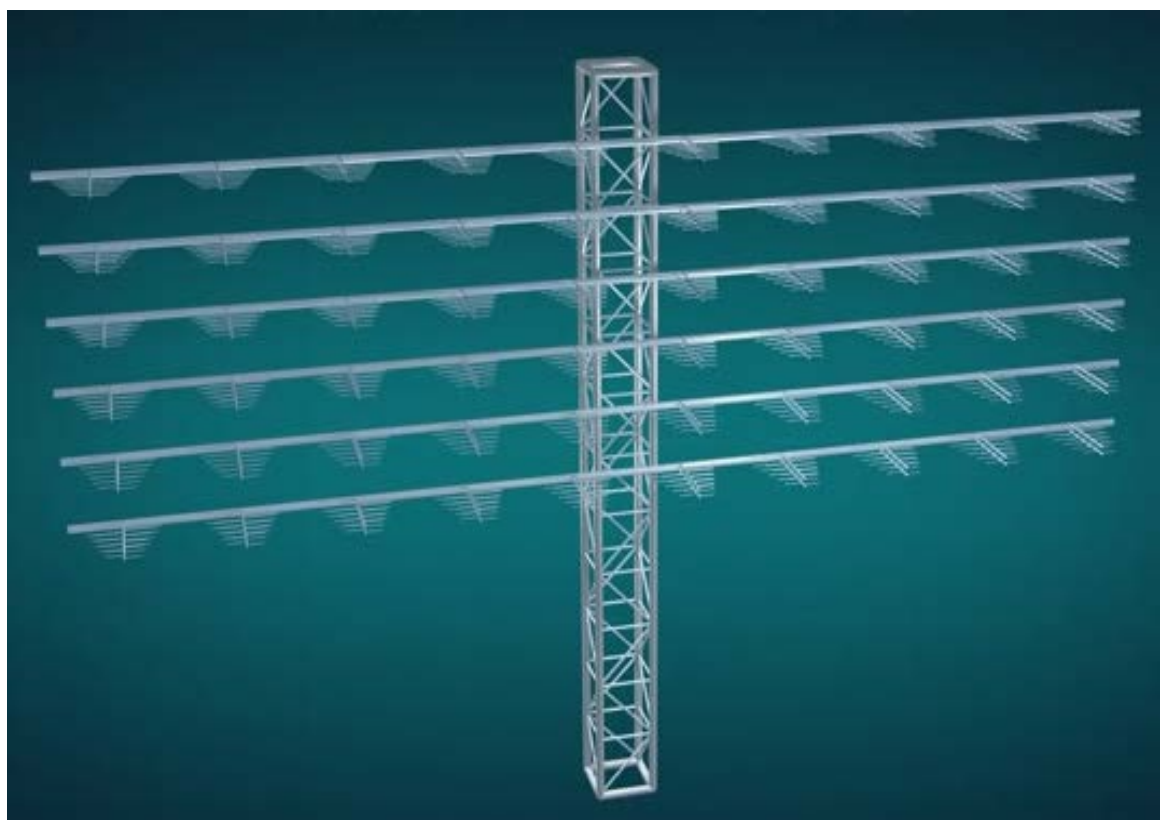

Figure 7. The antenna array.

The design result of each step is displayed to the students and the correctness of the design is verified. Finally, the performance of the reconstructed antenna array is compared with the actual project antenna, such as the appearance size, gain and beam width. And the existing problems and the details needing attention in the engineering design are pointed out. Through the OVP Blended Teaching Method, students can really understand the design idea of antennas, truly grasp the working principle of engineering practice, and penetrate the fusion of cross-disciplinary knowledge points, which also helps to enhance the creativity of students.

\section{Conclusion}

The OVP Blended Teaching Method is the organic integration and further improvement of blended teaching and project-based teaching. It is a diversified teaching method that not only pays attention to the organization of teaching content, but also highlights the design of teaching process and the application of teaching means. In terms of teaching methods, the network has been fully used. More attention has been paid to the typical, cutting-edge and leading practical projects in the project selection. The OVP blended teaching method focuses on the engineering reorganization of teaching content, and emphasizes the combination, re-collocation and how to better connect some knowledge points. This method not only emphasizes that the setting of teaching content should be scientific and reasonable with clear objectives, but also requires that teachers should have solid and comprehensive professional skills and rich engineering experience. For students, they can continuously improve their logical thinking ability, problem-solving innovation ability, teamwork cooperation ability and self-realization motivation ability. 


\section{Conflicts of Interest}

The authors declare no conflicts of interest regarding the publication of this paper.

\section{References}

Cao, W.-P., Zhang, Y., Su, M., \& Chen, W.-J. (2017). "Microwave Technology and Antennas" Course Explores: Integrating Theory with Practice. Science and Technology Innovation Herald, 15, 226-227.

Li, Z. (2018). On Teaching Mode of Engineering Mobile Micro-Courses-Take Microwave Technology and Antenna Course as an Example. Journal of Higher Education, No. 1, 82-83.

Ping, X.-W., Li, L., \& Yin, X.-H. (2017). Discussion on Teaching Methods for "Microwave Technique and Antenna". Education Teaching Forum, 17, 197-198.

Wang, Y., Deng, H.-W., Chen, W.-Y., \& Zhang, L. (2018). Investigation and Analysis of Teaching Effect for Microwave Technologies and Antennas. Journal of Electrical \& Electronic Education, 40, 10-14. 